\title{
Evaluation of interventions to reduce air pollution from biomass smoke on mortality in Launceston, Australia: retrospective analysis of daily mortality, 1994-2007
}

\author{
(c) $(1)$ (8) OPEN ACCESS
}

\author{
Fay $\mathrm{H}$ Johnston research fellow ${ }^{1}$, Ivan $\mathrm{C}$ Hanigan research associate ${ }^{23}$, Sarah $\mathrm{B}$ Henderson \\ epidemiologist ${ }^{4}$, Geoffrey G Morgan associate professor ${ }^{56}$
}

${ }^{1}$ Menzies Research Institute Tasmania and Rural Clinical School, University of Tasmania, Tasmania, Australia; ${ }^{2}$ National Centre for Epidemiology and Population Health, Australian National University ; ${ }^{3}$ School of Plant Science, University of Tasmania, Tasmania, Australia; ${ }^{4}$ British Colombia Centre for Disease Control, Vancouver, Canada; ${ }^{5}$ University Centre for Rural Health-North Coast, University of Sydney, Sydney, Australia; ${ }^{6}$ Northern New South Wales Local Health District, New South Wales, Australia

\begin{abstract}
Objective To assess the effect of reductions in air pollution from biomass smoke on daily mortality.

Design Age stratified time series analysis of daily mortality with Poisson regression models adjusted for the effects of temperature, humidity, day of week, respiratory epidemics, and secular mortality trends, applied to an intervention and control community.

Setting Central Launceston, Australia, a town in which coordinated strategies were implemented to reduce pollution from wood smoke and central Hobart, a comparable city in which there were no specific air quality interventions.

Participants 67000 residents of central Launceston and 148000 residents of central Hobart (at 2001 census).

Interventions Community education campaigns, enforcement of environmental regulations, and a wood heater replacement programme to reduce ambient pollution from residential wood stoves started in the winter of 2001

Main outcome measures Changes in daily all cause, cardiovascular, and respiratory mortality during the 6.5 year periods before and after June 2001 in Launceston and Hobart.

Results Mean daily wintertime concentration of $\mathrm{PM}_{10}$ (particulate matter with particle size $<10 \mu \mathrm{m}$ diameter) fell from $44 \mu \mathrm{g} / \mathrm{m}^{3}$ during 1994-2000 to $27 \mu \mathrm{g} / \mathrm{m}^{3}$ during 2001-07 in Launceston. The period of improved air quality was associated with small non-significant reductions in annual mortality. In males the observed reductions in annual mortality were larger and significant for all cause $(-11.4 \%, 95 \%$ confidence interval
\end{abstract}

$-19.2 \%$ to $-2.9 \% ; P=0.01)$, cardiovascular $(-17.9 \%,-30.6 \%$ to $-2.8 \%$; $\mathrm{P}=0.02)$, and respiratory $(-22.8 \%,-40.6 \%$ to $0.3 \% ; \mathrm{P}=0.05)$ mortality. In wintertime reductions in cardiovascular $(-19.6 \%,-36.3 \%$ to $1.5 \%$; $\mathrm{P}=0.06)$ and respiratory $(-27.9 \%,-49.5 \%$ to $3.1 \% ; \mathrm{P}=0.07)$ mortality were of borderline significance (males and females combined). There were no significant changes in mortality in the control city of Hobart.

Conclusions Decreased air pollution from ambient biomass smoke was associated with reduced annual mortality in males and with reduced cardiovascular and respiratory mortality during winter months.

\section{Introduction}

Despite a vast amount of literature on the health effects of air pollution, few studies have investigated shifts in outcomes with public health interventions to improve ambient air quality. Previous examples of such studies include reduced smoke pollution in winter from biomass in a small community in Montana, ${ }^{1}$ the temporary closure of a steel mill in Utah, ${ }^{2-5}$ the reduction of the sulphur content of petrol in Hong Kong, ${ }^{6}$ the cessation of coal sales in Dublin, ${ }^{7}$ and the evaluation of more gradual improvements in urban air quality in Germany, ${ }^{8}$ Switzerland, ${ }^{9}$ and the United States. ${ }^{10}$ These studies have reported decreases in a wide range of health outcomes associated with reductions in exposure to air pollution, including respiratory symptoms, mortality, and premature birth, and they have helped to quantify the health benefits of improved air quality. We assessed changes in mortality associated with an intervention to reduce ambient biomass smoke from domestic wood heaters.

Correspondence to: F H Johnston fay.johnston@utas.edu.au

Extra material supplied by the author (see http://www.bmj.com/content/345/bmj.e8446?tab=related\#webextra)

Appendix 1: Sensitivity analysis showing influence of varying width of moving average used to smooth daily mortality data in reference population of Tasmania

Appendix 2: Analyses using single combined models with an interaction term for the period ${ }^{*}$ city effect to statistically compare results for individual cities 
Biomass smoke is produced by the combustion of organic matter and includes emissions from domestic solid fuel use and landscape fires, with both indoor and outdoor sources contributing to the global burden of mortality. ${ }^{11}{ }^{12}$ While most research on the health effects of biomass smoke has concentrated on fine particulate matter (with particle size $<2.5 \mu \mathrm{m}$ diameter; $\mathrm{PM}_{2.5}$ ) as the primary pollutant of concern, the complex smoke mixture contains numerous toxic co-pollutants, including volatile organic compounds and gases..$^{13}$ The toxicology and epidemiology of biomass smoke have been less well characterised than that of particulate emissions from industry and transportation. ${ }^{14}$ Exposure to ambient biomass smoke, however, has been clearly associated with adverse respiratory outcomes and mortality, ${ }^{14}$ and evidence is emerging for associations with adverse cardiovascular outcomes. ${ }^{15} 16$ Intervention studies in Central America have replaced open cooking fires in dwellings with vented stoves to reduce indoor pollution from biomass smoke. Reported health improvements in the intervention groups include fewer respiratory symptoms, ${ }^{17}$ lower blood pressure, ${ }^{18}$ and babies with higher birth weights. ${ }^{19}$ In Canada, an intervention using air filters to reduce indoor particulate matter from wood heaters found that biological markers of inflammation and endothelial dysfunction were reduced, ${ }^{20}$ while in the US a $5 \mu \mathrm{g} / \mathrm{m}^{3}$ reduction in outdoor fine particulate matter from biomass smoke was associated with reduced wheeze and respiratory infections in children. ${ }^{1}$

We assess the mortality changes associated with improvements to air quality after coordinated government interventions to reduce ambient air pollution from indoor wood stoves in the Tasmanian city of Launceston. We also use the same methods on a comparable population in the Tasmanian city of Hobart, which did not have any air quality interventions. We compared daily annual and wintertime all cause, cardiovascular, and respiratory mortality rates during a 6.5 year period of documented poor air quality in Launceston, with a 6.5 year period of improved air quality that followed the government funded interventions.

\section{Methods}

\section{Setting}

The Australian state of Tasmania (population 472000 in 2001) is an island to the south of the continent, characterised by a colder and wetter climate than the rest of the Australia. Launceston (population 67000 in 2001) is the second largest city in Tasmania and serves as the regional capital and tertiary medical referral centre for the northern part of the state. Hobart (population 148000 in 2001) is the capital of Tasmania and the tertiary medical referral centre for the southern part of the state (fig $1 \Downarrow$ ).

During the late 1980s and early 1990s, wood stoves became increasing popular for home heating throughout Tasmania. The impact on air quality was particularly severe in Launceston, which is in a river valley where both topographical and meteorological conditions limit atmospheric dispersion of air pollution (fig $2 \Downarrow$ ). ${ }^{21}$ During the 1990 s, $66 \%$ of Launceston households used domestic wood stoves as the main source of heating, ${ }^{22}$ and emissions from these accounted for an estimated $85 \%$ of particulate air pollution in winter. ${ }^{23}$ The absolute number of wood heaters was estimated to be 17500 in the year $2000 .^{24}$

\section{Pollution monitoring}

In response to the perceived worsening of air quality in Launceston, a comprehensive monitoring campaign was started in 1991 to describe the spatial pattern of air pollution and to select the most appropriate site for long term monitoring of air quality. Simultaneous daily monitoring of concentrations of particulate matter less than $10 \mu \mathrm{m}$ in diameter $\left(\mathrm{PM}_{10}\right)$ was conducted at five sites in 1991-93 with gravimetric sampling methods. ${ }^{25}$ Measurements were found to be highly correlated with each other, except at one site to the east of the city where lower concentrations of particulate matter were generally recorded. ${ }^{25}$ After these studies a representative site was selected for ongoing monitoring of the air quality of central Launceston and the 24 hour $\mathrm{PM}_{10}$ concentration was measured on a one in six day cycle from 1994 to 1997. Starting in May 1997 measurements were taken daily during winter, and starting in June 2001 measurements were taken daily all year. The study population was drawn from four statistical local areas (SLAs) within the city of Launceston for which the long term monitoring site was known to be representative. ${ }^{25} \mathrm{We}$ report $\mathrm{PM}_{10}$ because this was the only size fraction that was measured throughout the study period. Since 2001, however, concentrations of $\mathrm{PM}_{2.5}$ have also been measured and these data show that the mean daily concentrations of $\mathrm{PM}_{2.5}$ are highly correlated with the concentrations of $\mathrm{PM}_{10}$, accounting for $50 \%$ of the annual average and $65 \%$ of the wintertime average. ${ }^{26}$

\section{Interventions}

The history of use of wood heaters, air pollution, and public health interventions in Launceston (fig $3 \Downarrow$ ) has been fully documented elsewhere. ${ }^{22}{ }^{24}$ Local governments started responding to concerns about air quality in 1994 after a detailed air quality study conducted by an expert working group from 1991 to $1993 .{ }^{25}$ These responses included the distribution of educational leaflets and the start of forecasts of wintertime air quality by the Bureau of Meteorology. They coincided with a state-wide marketing campaign by the local electricity supplier, promoting electricity as an affordable and non-polluting alternative (as most power in Tasmania is generated from hydroelectric power stations). During the 1990s there was a gradual decline in the proportion of homes heated primarily by wood throughout Tasmania and a gradual increase in the proportion heated by electricity. ${ }^{27}$ While air pollution slowly began to improve during this time period, ${ }^{22}$ substantive improvements in air quality did not occur until the start of coordinated government interventions in 2001. These included the Launceston Wood Heater Replacement Program, a \$A2.05m $(£ 1.34 \mathrm{~m}, € 1.66 \mathrm{~m})$ intervention funded through the Australian Natural Heritage Trust in July 2001 to June $2004 .^{22}$ This scheme greatly accelerated the general trend for home owners to replace wood with electricity as their primary source of domestic heating. By the end of the programme, the prevalence of wood stoves in Launceston had fallen from $66 \%$ to $30 \%$ of all households. ${ }^{22}$ Follow-up surveys indicated that many wood heaters were decommissioned during this time without support from the government programme. ${ }^{22}$ In addition to facilitating an overall reduction in the prevalence of wood heaters, the interventions also contributed to reducing pollution through improved operation of existing wood heaters by media advertising by the local council, school based education campaigns, and employment of environmental officers through the local council to monitor chimneys and provide targeted education, and, if necessary, infringement notices to home owners whose chimneys continued to emit excessive amounts of smoke after initial educational contact. A marked improvement in wintertime air quality coincided with the start of these interventions as illustrated by the photos in figure 2 and the $\mathrm{PM}_{10}$ data in figure 3 . 


\section{Meteorological data}

We obtained data on daily weather from the Bureau of Meteorology for three weather stations in central Launceston and five weather stations in central Hobart. ${ }^{28}$ For each city we calculated the average of the daily mean temperature and humidity inversely weighted by the distance of each weather station from the population weighted centre of the city. ${ }^{29}$

\section{Population and outcome data}

Population estimates were derived from the estimated resident population datasets available from the Australian Bureau of Statistics. ${ }^{30}$ These were linearly interpolated by day between the estimated populations on 30 June of each census year (1991, 1996, 2001, and 2006) for the 14 year period from 1994 to 2007. Estimates were derived for Launceston, Hobart, and the rest of Tasmania.

Mortality data were obtained from Australian Bureau of Statistics. These data undergo considerable auditing for quality before being released for publication. ${ }^{31}{ }^{32}$ Causes of death were categorised according to the international classification of diseases (ICD) coding ${ }^{33}$ into all cause (non-trauma), cardiovascular, and respiratory deaths (table $1 \Downarrow$ ). Mortality data from January 1994 to November 2007 were included in the analysis. ICD coding changed from version 9 to version 10 during the study period, and we followed the mapping of the Australian National Casemix and Classification Centre to ensure that extracted codes included the same causes of death before and after the change in coding. ${ }^{33}$ Hospital admissions data were provided by the Tasmania Department of Health and Human Services and were used to identify epidemics of respiratory infections by extracting the daily counts for admissions for pneumonia and flu (ICD9-9 480-487 or 507; ICD-10 J10-18 and J69-70).

\section{Statistical analyses}

We calculated annual concentrations of $\mathrm{PM}_{10}$ with one in six day sampling for the 1994-2000 period and daily monitoring data for the 2001-07 period. Winter (June, July, and August) $\mathrm{PM}_{10}$ concentrations were calculated from daily monitoring data from 1997. We used $t$ tests to compare mean annual and wintertime concentrations from before and after the intervention periods.

Daily direct age standardised mortality rates for all of Tasmania, Launceston, and Hobart, were calculated and aggregated to describe the annual and wintertime mortality rates in the periods before and after the intervention (table $2 \Downarrow$ ).

The effect of the intervention on all cause, cardiovascular, and respiratory mortality was assessed with age stratified time series Poisson regression models. The periods before and after the intervention were included as an indicator variable, and the interpolated age specific populations were used as an offset. ${ }^{34}$ All models controlled for the effects of meteorology, epidemics of respiratory infections, and secular trends in daily mortality in Tasmania with the following equation:

$\log \left(\mathrm{O}_{\mathrm{ij}}\right)=$ period $+\operatorname{age}_{\mathrm{j}}+\mathrm{T}_{\mathrm{i}}+\mathrm{T}_{\mathrm{i}-2}+\mathrm{H}_{\mathrm{i}}+\mathrm{H}_{\mathrm{i}-2}+\mathrm{DOW}_{\mathrm{i}}+\mathrm{flu}_{\mathrm{i}}+$ SecularTrend $+\operatorname{offset}\left(\log \left(\operatorname{Pop}_{\mathrm{ij}}\right)\right)$

where: $\mathrm{O}_{\mathrm{ij}}=$ observed number of cases on day $\mathrm{i}_{\mathrm{i}}$ age $\mathrm{j}_{\mathrm{j}}$; period $=$ indicator variable for periods before and after the intervention; age $=$ age groups by 15 year intervals to age 74 , then 5 year intervals to 84 , and ages $\geq 85 ; \mathrm{T}_{\mathrm{i}}=$ daily mean temperature $\left({ }^{\circ} \mathrm{C}\right)$; $\mathrm{T}_{\mathrm{i}-2}=$ average of three day lagged temperature day $_{\mathrm{i}}\left({ }^{\circ} \mathrm{C}\right) ; \mathrm{H}_{\mathrm{i}}=$ daily mean dew point $\left({ }^{\circ} \mathrm{C}\right) ; \mathrm{H}_{\mathrm{i}-2}=$ average of three day lagged dew point $\left({ }^{\circ} \mathrm{C}\right)$; flu $=$ indicator variable for days when the 14 day moving average of hospital admissions for flu and pneumonia in Tasmania exceeded the 95th centile; SecularTrend $=$ the 150 day moving average of the daily directly standardised cause specific mortality rates for Tasmania (excluding the intervention population of Launceston); and $\mathrm{Pop}_{\mathrm{ij}}=$ interpolated population on day in age $_{\mathrm{j}}$.

We conducted an identical statistical analysis for the control city of Hobart, after excluding its population from the data used to calculate secular mortality trends in Tasmania. We also conducted a subgroup analysis by sex.

We tested the sensitivity of our results to the use of different smoothing windows to calculate the state-wide secular trends in mortality; the definition of epidemics of respiratory infections (based on deaths from respiratory infections rather than hospital admissions for pneumonia or influenza); the use of indirect and direct age standardised mortality rates in the Poisson regression models (instead of age stratified regression); the inclusion of the winter of 2001 in the period before the intervention rather than the period after the intervention; and the use of the population of Northern Tasmania (where Launceston is situated) rather than all of Tasmania as the reference population for secular mortality trends.

\section{Results}

Air quality changed significantly over the study period (fig $3 \Downarrow$ ). The annual mean concentration of $\mathrm{PM}_{10}$ before the intervention was $23.7 \mu \mathrm{g} / \mathrm{m}^{3}$, based on the one in six day measurement cycle in 1997-2000 $(\mathrm{n}=237)$. This was higher $(\mathrm{P}<0.001)$ than the annual mean of $18.4 \mu \mathrm{g} / \mathrm{m}^{3}$ after the intervention, based on the average of daily measurements in 2001-07 $(n=2039)$. There was also a significant $(\mathrm{P}<0.001)$ decrease in the wintertime mean concentration of $\mathrm{PM}_{10}$ from $43.6 \mu \mathrm{g} / \mathrm{m}^{3}$ before the intervention period to $27.0 \mu \mathrm{g} / \mathrm{m}^{3}$ after the intervention (fig 3). $\Downarrow$

The mean annual number of all cause deaths in Launceston was $577,42 \%$ (243) of which were cardiovascular and 9\% (54) of which were respiratory (table 1$). \Downarrow$

There was a general trend towards reduced all cause, cardiovascular, and respiratory mortality throughout Tasmania during the study period, with the greatest magnitude observed for cardiovascular mortality (table 2). The reduction in respiratory mortality rates during winter months was larger in Launceston than in Hobart and the rest of Tasmania (table 2). $\Downarrow$

We assessed the changes in mortality associated with the period of improved air quality (1 July 2001 to 30 December 2007) for the entire year and for winter months only after adjusting for the influence of daily meteorology, respiratory epidemics, population age structure, and secular mortality trends (table $3 \Downarrow$ ). In the intervention community of Launceston, the period of improved air quality was associated with non-significant reductions in cardiovascular and respiratory mortality, which were not generally observed in the non-intervention community city of Hobart. In males, however the reductions in mortality in Launceston were large and significant for all cause $(-11.4 \%$, $95 \%$ confidence interval $-19.2 \%$ to $-2.9 \% ; \mathrm{P}=0.01)$, cardiovascular $(-17.9 \%,-30.6 \%$ to $-2.8 \% ; \mathrm{P}=0.02)$, and respiratory $(-22.8 \%,-40.6 \%$ to $0.3 \% ; \mathrm{P}=0.05)$ mortality.

When we restricted analyses to the winter months, the reductions in cardiovascular $(-19.6 \%,-36.3 \%$ to $1.5 \% ; \mathrm{P}=0.06)$ and respiratory $(27.9 \%,-49.5 \%$ to $3.1 \% ; \mathrm{P}=0.07)$ mortality (males and females combined) were of borderline significance (table $3 \Downarrow)$. There were no significant mortality changes in the non-intervention community of Hobart (table 3 ). 


\section{Sensitivity analyses}

Our results were sensitive to the window of smoothing that we used to calculate the secular trends in mortality in the rest of Tasmania. We tested a range of smoothing intervals from a 30 day moving average increasing in units of 30 days to a 300 day moving average. When we applied moving average intervals of 120 days or fewer, the point estimates for the effect of the intervention corresponded to greater reductions in mortality (see appendix 1). At smoothing intervals of 120 days or longer, the point estimates were more stable but the width of the confidence intervals gradually increased. For this reason we have taken a conservative approach and report results from analyses using a moving average interval of 150 days.

These results were robust to different methods of demographic adjustment and the different definitions of respiratory epidemics. We found similar results when we repeated the analysis with the winter of 2001 included in the period before rather than in the period after the intervention. When we used data from Northern Tasmania instead of all of Tasmania to determine secular mortality trends, there was a slightly greater reduction in mortality associated with the period after the intervention in Launceston.

\section{Discussion}

\section{Summary of main findings}

Improved air quality after coordinated interventions in the study community of Launceston, Tasmania, was associated with reductions in all cause, cardiovascular, and respiratory mortality. This trend was greatest for wintertime cardiovascular and respiratory mortality. In sex specific analyses of annual mortality, associations were stronger and of greater magnitude in males.

\section{Strengths and limitations of the study}

Examples of population level environmental interventions are rare. The major strength of this study was our ability to investigate whether an intervention to reduce outdoor biomass smoke from domestic wood heaters was associated with a measurable reduction in mortality. Another strength was our ability to compare effects between the intervention population (Launceston) and a control population (Hobart). We report the results of independent statistical models for each city because this fulfilled our objective of assessing whether the intervention was associated with mortality changes in Launceston. Combined models using pooled data from both cities with an interaction term indicated that the differences between the two populations were significant for the reduction in annual cardiovascular mortality (males and females combined) and for annual all cause mortality in men (see appendix 2). An important limitation was the relatively small study population, which reduced the statistical power of our study. Although the magnitude of most associations was relatively large, confidence intervals were wide. This was especially the case for respiratory outcomes which comprised just $10 \%$ of all deaths.

\section{Potential confounding factors}

We were able to measure and adjust for known and measurable confounders such as age, temperature, humidity, and respiratory epidemics. It is challenging, however, to separate the influence of secular trends in mortality. We included smooth daily mortality data from all of Tasmania to adjust for secular trends because the entire state has similar distributions of health outcomes, socioeconomic status, and demographic structure. ${ }^{35}$
The changing prevalence of population risk factors through time, such as smoking and diabetes, is likely to have been similar. $^{35}$

\section{Comparison with other studies}

We found three similar intervention studies. In a comparable intervention in the community of Libby, Montana, older wood heaters were exchanged with new, less polluting models during in the winter of 2006-07. Concentrations of fine particulate matter $\left(\mathrm{PM}_{2.5}\right)$ fell from a mean of $27.2 \mu \mathrm{g} / \mathrm{m}^{3}$ in the two winters before the intervention to $19.7 \mu \mathrm{g} / \mathrm{m}^{3}$ for two winters after. The respiratory heath of children was assessed by repeated annual surveys of their parents. A reduction of $5 \mu \mathrm{g} / \mathrm{m}^{3}$ in $\mathrm{PM}_{2.5}$ was associated with a $27 \%$ (95\% confidence interval $3 \%$ to $45 \%$ ) reduction in wheeze and even larger reductions in respiratory infections, including flu $(52 \%, 43 \%$ to $61 \%)$ and throat infections $(45 \%, 29 \%$ to $58 \%) .{ }^{1}$

Other studies have evaluated changes in mortality after interventions to reduce the sulphur content of petrol in Hong Kong and after the ban of coal sales for domestic heating in Dublin. In Hong Kong there was a documented $45 \%$ decline in mean ambient concentration of sulphur dioxide over five years, with no significant change in the ambient concentration of particulate matter after the intervention. ${ }^{6}$ The reported outcomes were a $2.1 \%(0.9 \%$ to $3.3 \%)$ decrease in all cause mortality, a $3.9 \%(6.2 \%$ to $1.6 \%)$ decrease in respiratory mortality, and a $2.0 \%$ (3.7\% to $0.3 \%$ ) decrease in cardiovascular mortality. These effects are small compared with our reported decrease in cardiovascular mortality, but they are more precise given the much larger population of Hong Kong compared with Launceston. As with our study, the observed decreases were higher during the colder months of the year. The Hong Kong study, however, did not include a non-intervention population to help disentangle any influence of long term trends in mortality. A second study evaluated the cessation of coal sales in Dublin, which resulted in $16 \%$ and $64 \%$ declines in wintertime concentrations of sulphur dioxide and black smoke, respectively. While associated declines in both respiratory and cardiovascular mortality were reported, ${ }^{7}$ these data are currently being reanalysed. ${ }^{36}$

\section{Further research}

Our results contribute to the emerging evidence for an association between exposure to biomass smoke and cardiovascular mortality. One time series study reported association between daily cardiovascular mortality and ambient biomass smoke pollution from wood heaters ${ }^{15}$ and another reported an association between biomass smoke from bushfires and out of hospital cardiac arrests. ${ }^{37}$ Other studies, however, have had inconclusive results, and further research is needed..$^{38-40}$

\section{Conclusions and implications for policy}

Observational studies are often the only practical option for evaluating the efficacy of population scale interventions. Adjustment for known and unknown confounding variables in observational studies is challenging. Given the clear and consistent difference in results between the intervention and the non-intervention populations, our findings suggest that the improved air quality in Launceston was associated with reductions in mortality. Furthermore, these results are consistent with the available literature concerning particulate air pollution. ${ }^{41}$ Our findings highlight the potential for important public health gains from interventions to reduce ambient pollution from biomass smoke. 


\section{What is already known on this topic}

Though much research has shown the adverse effects of air pollution on health, few studies have investigated shifts in health outcomes associated with public health interventions to improve ambient air quality

A previous intervention study found that reduced outdoor wood smoke was associated with improvements in children's respiratory health

\section{What this study adds}

Coordinated interventions, including community education, law enforcement, and incentives to reduce pollution from domestic wood heaters, substantially improved winter air quality in Launceston, Tasmania

The period of improved air quality was associated with an overall trend towards reduced cardiovascular and respiratory mortality

We thank Douglas Dockery and Mark Clements for their support in development of the statistical methods. Grant Williamson assisted with preparation of the figures. James Markos provided the photographs used in figure 2.

Contributors: FHJ conceived the study, contributed to study design, and prepared the manuscript. ICH contributed to study design, conducted the analyses, and contributed to the manuscript. SBH and GGM contributed to study design and preparation of the manuscript. All authors read and approved the manuscript. All authors had full access to all of the data in the study and can take responsibility for the integrity of the data and the accuracy of the data analysis. $\mathrm{FHJ}$ and $\mathrm{ICH}$ are guarantors. Funding: This study was supported by the Australian Research Council (LP0882048), the Tasmanian Government Department of Health and Human Services, and the Environment Protection Authority Tasmania. The funding agencies had no role in the study design, analysis, or preparation of the manuscript.

Competing interests: All authors have completed the ICMJE uniform disclosure form at www.icmje.org/coi_disclosure.pdf (available on request from the corresponding author) and declare: no support from any organisation for the submitted work; no financial relationships with any organisations that might have an interest in the submitted work in the previous three years; no other relationships or activities that could appear to have influenced the submitted work.

Ethical approval: This study was approved by the ANU human research ethics committee (2008/199) and the Tasmanian human research ethics committee (H0010047).

Data sharing: No further data are available.

1 Noonan CW, Ward TJ, Navidi W, Sheppard L. A rural community intervention targeting biomass combustion sources: effects on air quality and reporting of children's respiratory outcomes. Occup Environ Med 2012;69:354-60.

2 Parker JD, Mendola P, Woodruff TJ. Preterm birth after the Utah Valley steel mill closure: a natural experiment. Epidemiology 2008;19:820-23

3 Pope CA. Particulate pollution and health: a review of the Utah valley experience. J Expo Anal Env Epid 1996;6:23.

4 Pope CA. Respiratory hospital admissions associated with $\mathrm{PM}_{10}$ pollution in Utah, Salt Lake, and Cache Valleys. Arch Environ Health 1991;46:90-97.

5 Pope CA, Schwartz J, Ransom MR. Daily mortality and $\mathrm{PM}_{10}$ pollution in Utah Valley. Arch Environ Health 1992;47:211-17.

6 Hedley AJ, Wong CM, Thach TQ, Ma S, Lam TH, Anderson HR. Cardiorespiratory and all-cause mortality after restrictions on sulphur content of fuel in Hong Kong: an intervention study. Lancet 2002;360:1646-52.

7 Clancy L, Goodman P, Sinclair H, Dockery DW. Effect of air-pollution control on death rates in Dublin, Ireland: an intervention study. Lancet 2002;360:1210-14.

8 Heinrich J, Hoelscher B, Frye C, Meyer I, Pitz M, Cyrys J, et al. Improved air quality in reunified Germany and decreases in respiratory symptoms. Epidemiology 2002;13:394-401.

9 Schindler C, Keidel D, Gerbase MW, Zemp E, Bettschart R, Brandli O, et al. Improvements in $\mathrm{PM}_{10}$-exposure and reduced rates of respiratory symptoms in a cohort of Swiss adults (SAPALDIA-study). Am J Respir Crit Care Med 2009;179:579-87.

10 Pope CA, Ezzati M, Dockery DW. Fine-particulate air pollution and life expectancy in the United States. N Engl J Med 2009;360:376-86.

11 Ezzati M, Lopez A, Rodgers A, Vander Hoorn S, Murray C. Selected major risk factors and global and regional burden of disease. Lancet 2002;360:1347-60

12 Johnston FH, Henderson SB, Chen Y, Randerson JT, Marlier M, DeFries RS, et al. Estimated global mortality attributable to smoke from landscape fires. Environ Health Perspect 2012;120:659-701.

13 Reid JS, Koppmann R, Eck TF, Eleuterio DP. A review of biomass burning emissions part II: intensive physical properties of biomass burning particles. Atmos Chem Phys 2005;5:799-825.

14 Naeher LP, Brauer M, Lipsett M, Zelikoff JT, Simpson CD, Koenig JQ, et al. Woodsmoke health effects: a review. Inhal Toxicol 2007:19:67-106.

15 Sanhueza PA, Torreblanca MA, Diaz-Robles LA, Schiappacasse LN, Silva MP, Astete TD. Particulate air pollution and health effects for cardiovascular and respiratory causes in Temuco, Chile: a wood-smoke-polluted urban area. J Air Waste Manag Assoc 2009;59:1481-8.
16 McGowan JA, Hider RN, Chacko E, Town Gl. Particulate air pollution and hospital admissions in Christchurch, New Zealand. Aust NZ J Publ Heal 2002;26:23-9.

17 Romieu I, Riojas-Rodriguez H, Marron-Mares AT, Schilmann A, Perez-Padilla R, Masera O. Improved biomass stove intervention in rural Mexico: impact on the respiratory health of women. Am J Respir Crit Care Med 2009;180:649-56.

18 McCracken JP, Smith KR, Díaz A, Mittleman MA, Schwartz J. Chimney stove intervention to reduce long-term wood smoke exposure lowers blood pressure among Guatemalan women. Environ Health Persp 2007;115:996-1001.

19 Thompson LM, Bruce N, Eskenazi B, Diaz A, Pope D, Smith KR. Impact of reduced maternal exposures to woodsmoke from an introduced chimney stove on newborn birth weight in rural Guatemala. Environ Health Persp 2011;119:1489-94.

20 Allen RW, Carlsten C, Karlen B, Leckie S, van Eeden S, Vedal S, et al. An air filter intervention study of endothelial function among healthy adults in a woodsmoke-impacted community. Am J Respir Crit Care Med 2011;183:1222-30.

21 Keywood MD, Ayers GP, Gras JL, Gillett RW, Cohen DD. Size distribution and sources of aerosol in Launceston, Australia, during winter 1997. J Air Waste Manag Assoc 2000;50:418-27.

22 CSIRO Atmospheric Research. Woodheaters in Launceston-impacts on air quality. Department of the Environment and Heritage, 2005:52.

23 Department of Infrastructure Water and the Environment (DPIWE). Discussion paper on air quality management and policy development in Launceston. Tasmanian Department of Infrastructure Water and the Environment, 2000.

24 Power M. Air pollution dispersion within the Tamar Valley [thesis]. University of Tasmania, 2001.

25 Lyons L. Air pollution, environmental and respiratory diseases, Launceston and Upper Tamar Valley Tasmania. Launceston City Council, 1996;63.24.

26 Environment Protection Authority Tasmania. Tasmanian air quality strategy. Tasmanian Department of Tourism, Arts and the Environment, 2006.

27 Australian Bureau of Statistics. Energy use and conservation. 2011. www.abs.gov.au/ AUSSTATS/abs@.nsf/Lookup/4602.0.55.001Main+Features1Mar\%202011? OpenDocument

28 National Climate Centre of the Bureau of Meteorology.Daily or three hourly weather data for bureau of meteorology stations. Bureau of Meteorology, 2010.

29 Hanigan IC, Hall G, Dear KB. A comparison of methods for calculating population exposure estimates of daily weather for health research. Int J Health Geogr 2006;5:38.

30 Australian Bureau of Statistics. Population estimates by age and sex, 2006. 2006. www. abs.gov.au/AUSSTATS/abs@.nst/allprimarymainfeatures/ 2F33D3E91BA0F08FCA2574A900130EE7?opendocument

31 Australian Bureau of Statistics. Quality declaration deaths, Australia, 2010. Canberra, 2012.www.abs.gov.au/AUSSTATS/abs@.ns//Latestproducts/3303.0Quality\% 20Declaration02010? opendocument\&tabname $=$ Notes \& prodno $=3303.0 \&$ issue $=2010 \&$ num $=\&$ view

32 Australian Bureau of Statistics. Causes of death Australia 1964-2007 (3303.0). Health Statistics Unit, 2010.www.abs.gov.au/ausstats/abs@.nsf $/ \mathrm{mf} / 3303.0$

33 National Casemix and Classification Centre. IDC-10 mapping tables. University of Wollongong, 2010.

34 Roalfe A, Holder R, Wilson S. Standardisation of rates using logistic regression: a comparison with the direct method. BMC Health Serv Res 2008;8:275.

35 Epidemiology Unit, Population Health. Health Indicators Tasmania. Department of Health and Human Services, 2008:124.

36 Dockery DW, Rich DQ, Goodman PG, Clancy L, Ohman-Strickland P, George P, et al. Effect of air pollution control on mortality and hospital admissions in Ireland. Health Effects Institute Annual Conference, Chicago, Illinois, April 2012. www.healtheffects.org/Pubs/ AnnualConference2012Program\&Abstracts.pdf

37 Dennekamp M, Erbas B, Sim M, Glass D, Keywood M, Abramson M, et al. Air pollution from bushfires and out of hospital cardiac arrests in Melbourne Australia. Epidemiology 2011;22:S53.

38 Johnston FH, Hanigan IC, Henderson SB, Morgan GG, Bowman DMJS. Extreme air pollution events from bushfires and dust storms and their association with mortality in Sydney, Australia 1994-2007. Environ Res 2011;111:811-6.

39 Hales S, Salmond C, Town Gl, Kjellstrom T, Woodward A. Daily mortality in relation to weather and air pollution in Christchurch, New Zealand. Aust NZ J Publ Heal 2000;24:89-91.

40 Morgan G, Sheppeard V, Khalaj B, Ayyar A, Lincoln D, Jalaludin B, et al. The effects of bushfire smoke on daily mortality and hospital admissions in Sydney, Australia, 1994 to 2002. Epidemiology 2010;21:47-55.

41 Zanobetti A, Schwartz J. The effect of fine and coarse particulate air pollution on mortality: a national analysis. Environ Health Persp 2009;117:898.

Accepted: 03 December 2012

\section{Cite this as: BMJ 2012;345:e8446}

This is an open-access article distributed under the terms of the Creative Commons Attribution Non-commercial License, which permits use, distribution, and reproduction in any medium, provided the original work is properly cited, the use is non commercial and is otherwise in compliance with the license. See: http://creativecommons.org/licenses/bync/2.0/ and http://creativecommons.org/licenses/by-nc/2.0/legalcode. 


\section{Tables}

Table 1| Mean number of deaths for all cause, cardiovascular, and respiratory mortality in Launceston, Tasmania, 1994-2007

\begin{tabular}{llcc} 
Mortality & \multicolumn{1}{c}{ ICD codes* } & Annual & Winter \\
All cause & ICD-9 $<800 ;$ ICD-10 A00-R99 & 577 & 158 \\
\hline Cardiovascular & ICD-9 390-459; ICD-10 I00-I99 (excl I67.3, I68, I88, 197.8, & 243 & 68 \\
\hline Respiratory & I97.9, I98), G45 (excl G45.3), G46, M30, M31, R58 & & 17 \\
& ICD-9 codes 460-519; ICD-10 J00-J99 (excl J95.4-J95.9), & 54 & \\
\hline
\end{tabular}

${ }^{*} \mathrm{ICD}$ (international classification of diseases) coding changed from version 9 to version 10 during study period. We followed mapping of National Casemix and Classification Centre to ensure that extracted codes included same causes of death before and after change in coding. ${ }^{33}$ 
Table 2| Annual and wintertime age standardised mortality in Tasmania, Launceston, and Hobart during calendar years 1994-2000 and 2001-07, before and after intervention to improve air quality in Launceston

\begin{tabular}{|c|c|c|c|}
\hline & \multicolumn{2}{|c|}{ Deaths per 1000 person years } & \multirow[b]{2}{*}{ Percent decrease $(95 \% \mathrm{Cl})$} \\
\hline & $1994-2000$ & 2001-07 & \\
\hline \multicolumn{4}{|c|}{ All Tasmania } \\
\hline \multicolumn{4}{|c|}{ All cause mortality: } \\
\hline All year & 8.33 & 7.12 & $14.6(5.2$ to 24.0$)$ \\
\hline Winter & 9.32 & 7.88 & 15.5 (6.4 to 24.6$)$ \\
\hline \multicolumn{4}{|c|}{ Cardiovascular mortality: } \\
\hline All year & 3.73 & 2.65 & 28.9 (5.6 to 42.2$)$ \\
\hline Winter & 4.28 & 2.96 & 31.1 (18.6 to 43.7$)$ \\
\hline \multicolumn{4}{|c|}{ Respiratory mortality: } \\
\hline All year & 0.78 & 0.62 & 20.5 (8.3 to 32.7$)$ \\
\hline Winter & 1.00 & 0.76 & 22.9 (7.6 to 38.3$)$ \\
\hline \multicolumn{4}{|c|}{ Launceston } \\
\hline \multicolumn{4}{|c|}{ All cause mortality: } \\
\hline All year & 8.57 & 7.42 & 13.4 (2.9 to 24.0$)$ \\
\hline Winter & 9.20 & 8.08 & 16.0 (3.9 to 28.2$)$ \\
\hline \multicolumn{4}{|c|}{ Cardiovascular mortality: } \\
\hline All year & 3.88 & 2.74 & 29.5 (14.0 to 45.1$)$ \\
\hline Winter & 4.52 & 2.96 & 34.4 (22.5 to 6.4$)$ \\
\hline \multicolumn{4}{|c|}{ Respiratory mortality: } \\
\hline All year & 0.86 & 0.64 & 24.6 (4.7 to 44.6$)$ \\
\hline Winter & 1.16 & 0.76 & 33.0 (4.6 to 61.4$)$ \\
\hline \multicolumn{4}{|l|}{ Hobart } \\
\hline \multicolumn{4}{|c|}{ All cause mortality: } \\
\hline All year & 8.25 & 7.22 & 12.5 (3.4 to 21.5$)$ \\
\hline Winter & 9.52 & 8.12 & 14.7 (5.1 to 24.2$)$ \\
\hline \multicolumn{4}{|c|}{ Cardiovascular mortality: } \\
\hline All year & 3.58 & 2.68 & 25.2 (12.6 to 37.7 ) \\
\hline Winter & 4.16 & 2.96 & 28.6 (14.7 to 42.5$)$ \\
\hline \multicolumn{4}{|c|}{ Respiratory mortality: } \\
\hline All year & 0.76 & 0.64 & 15.7 (0.5 to 30.9$)$ \\
\hline Winter & 1.00 & 0.88 & $12.3(-13.4$ to 7.9$)$ \\
\hline
\end{tabular}


Table 3| Percentage change ${ }^{\star}$ in all cause, cardiovascular, and respiratory mortality in Launceston and Hobart, Tasmania, from January 1994-May 2001 to June 2001-November 2007. Years 2001-07 correspond with period of improved air quality after series of coordinated interventions in Launceston

\begin{tabular}{|c|c|c|c|c|}
\hline & \multicolumn{2}{|c|}{ Launceston (intervention) } & \multicolumn{2}{|c|}{ Hobart (control) } \\
\hline & Percent change $(95 \% \mathrm{Cl})$ & $P$ value & Percent change $(95 \% \mathrm{Cl})$ & $P$ value \\
\hline \multicolumn{5}{|c|}{ All year-males and females combined } \\
\hline All cause mortality & $-2.7(-8.7$ to 3.7$)$ & 0.40 & $1.4(-3.0$ to 6.0$)$ & 0.54 \\
\hline Cardiovascular mortality & $-4.9(-15.5$ to 7.0$)$ & 0.40 & $0.9(-7.1$ to 9.6$)$ & 0.83 \\
\hline Respiratory mortality & $-8.5(-23.2$ to 9.0$)$ & 0.32 & $4.8(-7.4$ to 18.6$)$ & 0.50 \\
\hline \multicolumn{5}{|l|}{ All year-males } \\
\hline All cause mortality & $-11.4(-19.2$ to -2.9$)$ & 0.01 & $0.7(-5.4$ to 7.2$)$ & 0.82 \\
\hline Cardiovascular mortality & $-17.9(-30.6$ to -2.8$)$ & 0.02 & $-7.1(-16.8$ to 3.8$)$ & 0.19 \\
\hline Respiratory mortality & $-22.8(-40.6$ to 0.3$)$ & 0.05 & $3.4(-13.1$ to 24.4$)$ & 0.67 \\
\hline \multicolumn{5}{|l|}{ All year-females } \\
\hline All cause mortality & $2.7(-5.3$ to 11.4$)$ & 0.52 & $-0.7(-6.3$ to 5.2$)$ & 0.80 \\
\hline Cardiovascular mortality & $2.3(-12.2$ to 19.3$)$ & 0.77 & $3.6(-7.6$ to 16.2$)$ & 0.54 \\
\hline Respiratory mortality & $1.0(-18.9$ to 24.4$)$ & 0.96 & $-1.4(-15.5$ to 15.1$)$ & 0.86 \\
\hline \multicolumn{5}{|c|}{ Wintertime-males and females combined } \\
\hline All cause mortality & $2.2(-14.1$ to 11.3$)$ & 0.73 & $-2.0(-10.2$ to 6.9$)$ & 0.64 \\
\hline Cardiovascular mortality & $-19.6(-36.3$ to 1.5$)$ & 0.06 & $-7.0(-20.8$ to 9.2$)$ & 0.38 \\
\hline Respiratory mortality & $-27.9(-49.5$ to 3.1$)$ & 0.07 & $8.0(-16.9$ to 40.4$)$ & 0.60 \\
\hline
\end{tabular}

*Adjusted for age structure, meteorological conditions, and secular mortality trends in Tasmania. 


\section{Figures}

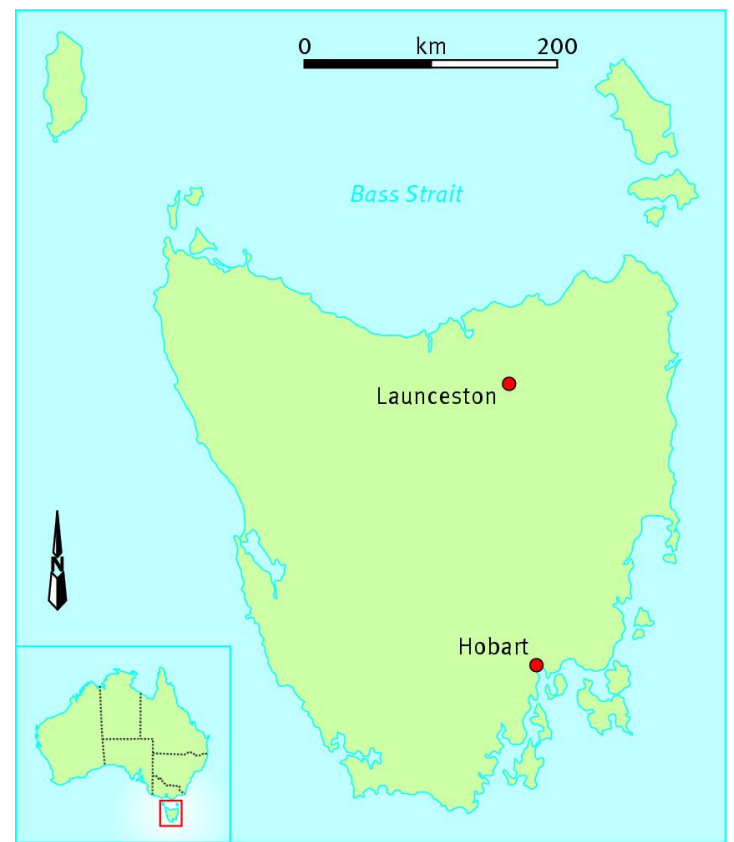

Fig 1 Map of Tasmania showing location of Launceston (intervention city) and Hobart (control)
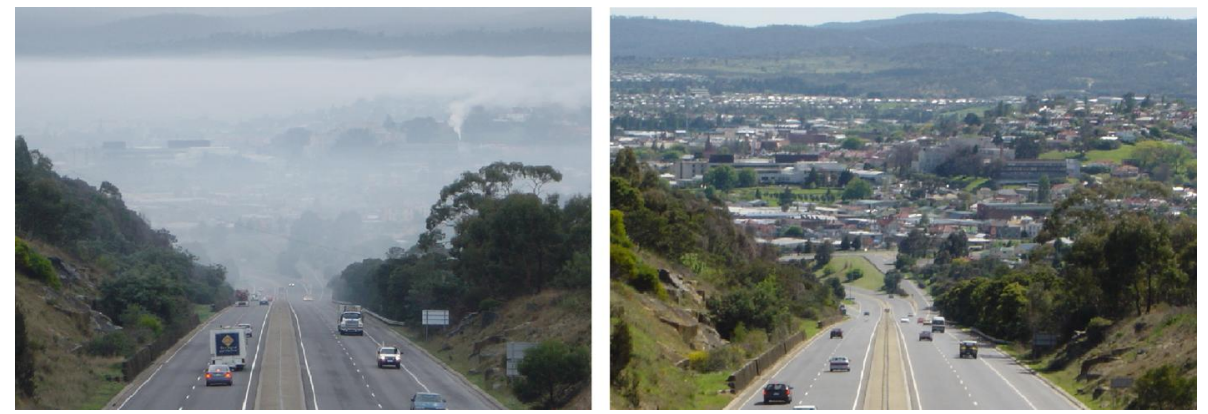

Fig 2 Launceston, Tasmania, showing reduced visibility associated with smoke from domestic wood heaters (left) and same view on clear day (right) 
- Daily average $\mathrm{PM}_{10}$ $\left(\mu \mathrm{g} / \mathrm{m}^{3}\right)$

Winter mean (where $>75 \%$ observed)

- Smoothed standardised daily mortality

- - Start of coordinated interventions

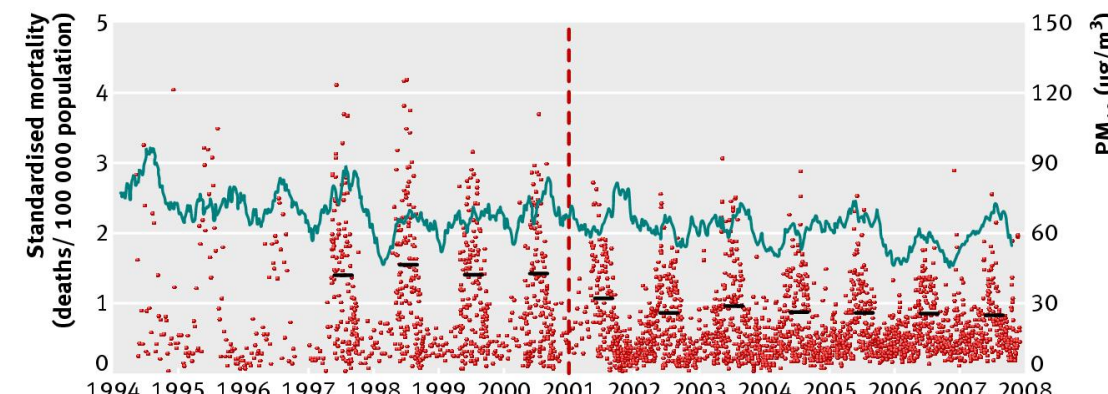

Antecedent events 1980-1994

\section{Study period}

Time (days)

80's: Incresing popularity of domestic wood heaters and increasing community perception of worsening air quality

91-94: An Expert Working Party was formed to provide the first detailed assessments of air quality and health, establishing the basis for subsequent monitoring and public education campaigns

\section{4-2008}

1994-2001: Period of poor air quality

Initial responses:

94-01: Detailed research projects on particular air pollution in the area 94-08: Tasmania wide marketing

campaign to promote electric heating

97-08: Winter air quality forecasts

issued by the Bureau of Meteorology

00-01: Distribution of educational

leaflets

Fig 3 Air quality interventions, air quality data, and directly aged standardised mortality in Launceston, Tasmania 1991-2007 